\title{
Compreensão de Padrões Através da Percepção de Vibrações Táteis em Dispositivos Móveis
}

\author{
Understanding Patterns Through Perception of Tactile Vibrations in Mobile Devices
}

FERREIRA, Guilherme Philippe Garcia; Doutor; Universidade Federal do Paraná

guilhermepgf@gmail.com

HEEMANN, Adriano; Doutor; Universidade Federal do Paraná

adriano.heemann@gmail.com

\section{Resumo}

O tato pode ser um importante canal informacional, entretanto seu alcance em dispositivos móveis ainda é incerto. Neste artigo, demonstra-se parte de um ensaio de interação que explora a percepção tátil vibracional frente a três aplicativos. Os ensaios realizados com usuários entre 17 e 36 anos buscam compreender os alcances da percepção tátil, considerando o reconhecimento de representações gráficas, reconhecimento de formas e a qualidade tátil. $O$ ensaio coleta a interpretação dos participantes frente as aplicações estudadas e desenvolve análises qualiquantitativas. Os resultados demonstram que dentro dos aspectos pesquisados a compreensão de informações táteis pode ocorrer através da percepção de diferentes vibrações. Entretanto, não fica claro se o uso de componentes vestíveis pode garantir resultados mais efetivos para a interação com objetos táteis. Ao final, são sugeridos desdobramentos desta pesquisa para novas investigações.

Palavras Chave: tato, dispositivos móveis, percepção e háptica.

\begin{abstract}
Touch can be an important informational channel, however its reach on mobile devices is still uncertain. In this paper, part of a user interaction trial is demonstrated that explores the vibrational tactile perception of three applications. The tests performed with users between the ages of 17 and 36 seek to understand the reach of tactile perception, considering the recognition of graphic representations, patterns recognition and tactile quality. The test collects the participants' interpretation of the applications studied and develops qualitative-quantitative analyzes. The results demonstrate that within the surveyed aspects the comprehension of tactile information can occur through the perception of different vibrations. However, it is not clear whether the use of wearable components can guarantee more effective results for the interaction with tactile objects. At the end, we suggest the implications of this research for further investigations.
\end{abstract}

Keywords: touch, mobile devices, perception and haptics. 


\section{Introdução}

A interação entre usuário e sistema, nos dispositivos móveis, possui como uma das principais funções a transferência de informações. O usuário se comunica com o sistema através da entrada de dados, que podem ser realizadas através dos gestos em tela, captura de fala ou imagem, entrada de texto entre outros; enquanto o sistema provém retorno ao usuário através de informações visuais, como texto e imagem; auditivas, como sons e alertas e através de padrões vibracionais. As vibrações nos dispositivos móveis produzem uma referencial que pode ser percebido através do tato, que embora seja um importante canal sensorial ainda é pouco explorado como meio informacional nos dispositivos móveis.

Dispositivos com tela sensível ao toque e com possibilidade do retorno tátil, tem a capacidade latente de incrementar o aprendizado, segundo Toennies et al. (2011). Para usuários normovisuais, os autores apontam que a informação tátil pode trazer mais dados ao que está sendo visualizado; para usuários com baixa visão, a informação pode ser facilitada através de referências táteis ou ainda depender exclusivamente do sentido tátil para ser adquirida. Assim, as interfaces e experiências táteis, em dispositivos móveis poderão ser um grande componente da aprendizagem em um futuro próximo.

Nesta direção Griffin e Gerber (1996 apud Liberto 2012, p. 75), identificam quatro fases da função educativa do tato; "consciência da qualidade tátil; conceito e reconhecimento da forma (reconhecimento da estrutura e da relação das partes com o todo); compreensão de representações gráficas e utilização de simbologia". Considerando os dispositivos móveis, a qualidade tátil pode ser compreendida como a resolução tátil; o conceito e reconhecimento envolve a forma e padrão com que a informação é transmitida, por exemplo como objeto único ou múltiplos objetos e objetos sobrepostos; a compreensão das representações é relacionada à maneira como são percebidos os objetos gráficos, ou seja a relação entre codificador e decodificador e sua efetividade já as simbologias indicam padrões de interação com o sistema.

Desta forma, este ensaio de interação apresenta uma investigação aplicada a dispositivos móveis onde se explora a relação perceptiva tátil, tratada neste contexto através do termo háptica também utilizado neste documento, frente a diferentes demandas cognitivas, como a qualidade tátil, reconhecimento de forma e compreensão de representações. Os dados coletados demonstram a interpretação dos participantes diante das aplicações estudadas e são analisados de modo quali-quantitativo.

\section{Metodologia}

O ensaio de interação desenvolvido explora a relação da percepção tátil através de três aplicativos executados em dispositivos móveis com sistema operacional Android 4.1.2. Os ensaios buscam compreender os alcances da percepção frente a diferentes demandas cognitivas, considerando os motores vibracionais atualmente disponíveis na maioria dos dispositivos móveis. O ensaio apresentado na sequência é descrito a partir dos seguintes itens: dispositivos utilizados no teste; participantes e ensaios de interação realizados.

\subsection{Dispositivos Utilizados}

Para o estudo foram utilizados dois smartphones modelo LG Optimus L7 II Dual P716. Um dos smartphones foi modificado para uso do motor vibracional em um componente vestível externo (anel háptico). A Figura 1 demonstra o componente "anel háptico" que é composto por materiais 
reciclados (tubo plástico secionado, elástico siliconado, EVA, motor vibracional, fita isolante na cor azul e cabo conector) realizado especificamente para este estudo, podendo ser facilmente replicado por outros pesquisadores. Para a passagem do cabo conector a capa foi alterada recebendo um sulco.

Figura 1 - Capa do aparelho com sulco para passagem do cabo.

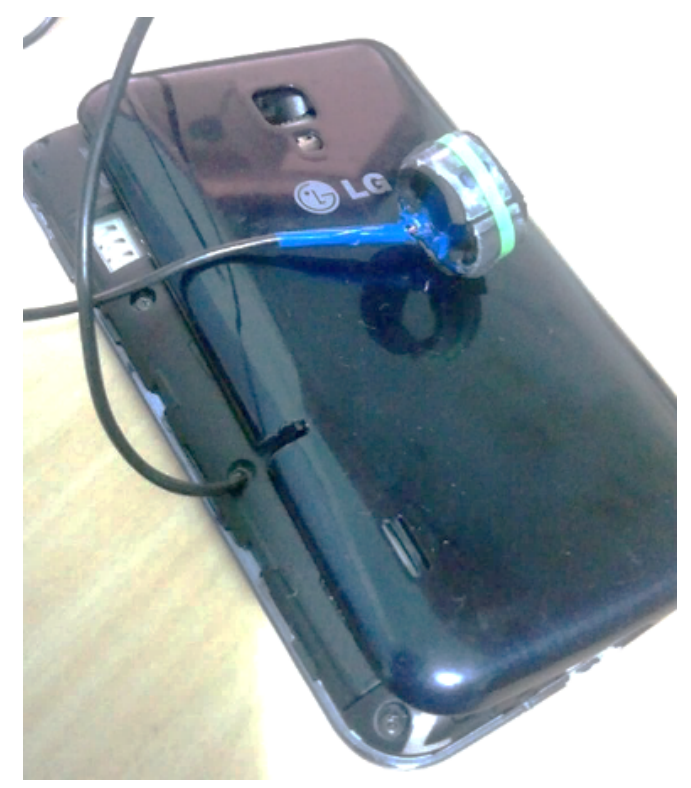

Fonte: Os autores (2017)

Em cada smartphone foram instalados aplicativos com retorno tátil selecionados para o estudo, Figura 2, em versão gratuita: a) Tactile Mobile Free, b)Haptic Memory Match e c) Haptic Mystery.

Figura 2 - Telas dos softwares estudados.
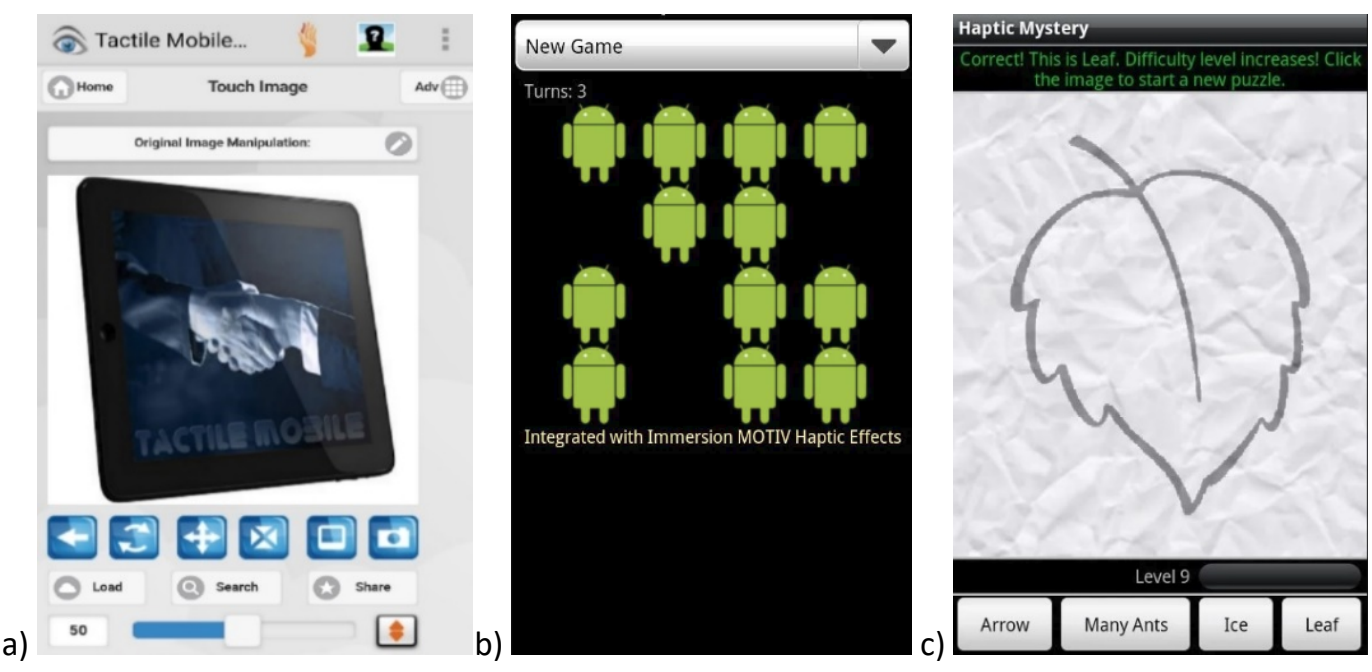

Fonte: Captura de tela dos autores (2017) 
a) Tactile Mobile Free: o aplicativo converte imagens para imagens com componente háptico. Como exemplo, um fundo preto pode representar vibração totalmente ativa e fundo branco totalmente inativa. Com este aplicativo buscou-se identificar se a qualidade tátil incrementa a informação percebida.

b) Haptic Memory Match: um jogo de memória baseado em matriz de ícones no qual é necessário encontrar pares de vibração. Na sua versão com maior complexidade, apresenta oito sinais táteis distintos em uma matriz $4 \times 4$. Este aplicativo foi utilizado para verificar 0 reconhecimento de forma.

c) Haptic Mystery: a interface apresenta um painel no qual é demonstrado um fundo branco com textura não distinguível e quatro opções de resposta. Durante a interação, o usuário utiliza o tato para rastrear a imagem escondida através das vibrações. Após a escolha da opção que julga mais adequada uma mensagem informa o usuário do acerto ou erro e a imagem háptica oculta é revelada. Com este aplicativo investigou-se a compreensão de representações gráficas.

\subsection{Participantes}

Trinta e três voluntários participaram deste ensaio. A amostra consistiu em 17 homens na faixa de 18 a 36 anos, com idade média de 23 anos; e 16 mulheres na faixa de 18 a 31 anos, com idade média de 22 anos, todos estudantes de graduação ou pós-graduação com conhecimento básico em inglês. Os participantes são normovisuais ou utilizam lentes corretivas. Nenhuma alteração congênita, danos ou lesões nas mãos que pudessem atrapalhar o entendimento do tato foram identificadas ou relatadas pelos participantes.

Na sequência, individualmente, foram esclarecidos os objetivos da pesquisa e realizada a leitura e assinatura de Termo de Consentimento Livre e Esclarecido (TCLE). Após, foi entregue a cada participante uma ficha contendo as questões do estudo a serem respondidas. Uma leitura das questões junto aos participantes e explicações adicionais foi realizada para reduzir possíveis dúvidas. $O$ ensaio de interação ocorreu em laboratório com iluminamento na bancada de estudo em 300 lux. Cada participante foi orientado a permanecer sentado durante todo o tempo do ensaio. Os smartphones utilizados foram configurados para iluminação máxima.

\subsection{Ensaio A - Atributos das Figuras Geométricas}

Neste ensaio, foram utilizadas duas imagens com elementos geométricos planos, no aplicativo Tactile Mobile Free, conforme Figura 3:

Figura 3 - Imagens Geométricas

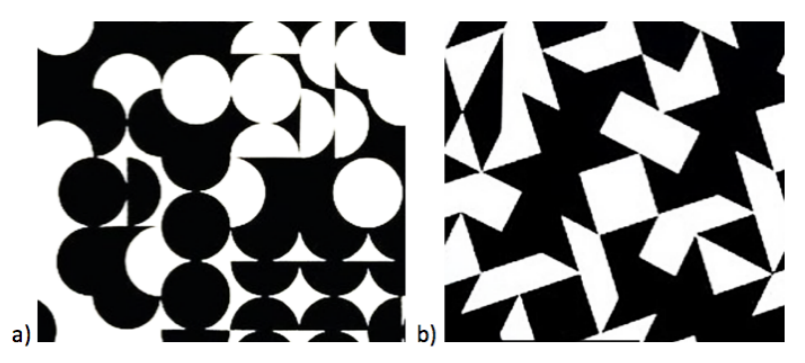

Fonte: Captura de tela dos autores (2017) 
A imagem a) apresenta como elementos formados por círculos e semi-círculos, enquanto a imagem b) possui elementos quadrados, retângulos e triângulos sobrepostos. Para reduzir relações significativas nenhuma das imagens selecionadas ao estudo apresenta formação de conjunto com representação simbólica ou gráfica. Os praticantes deste ensaio foram submetidos a visualização somente da imagem a) ou b) e a interação vibracional ou com anel háptico com a imagem restante, conforme Figura 4:

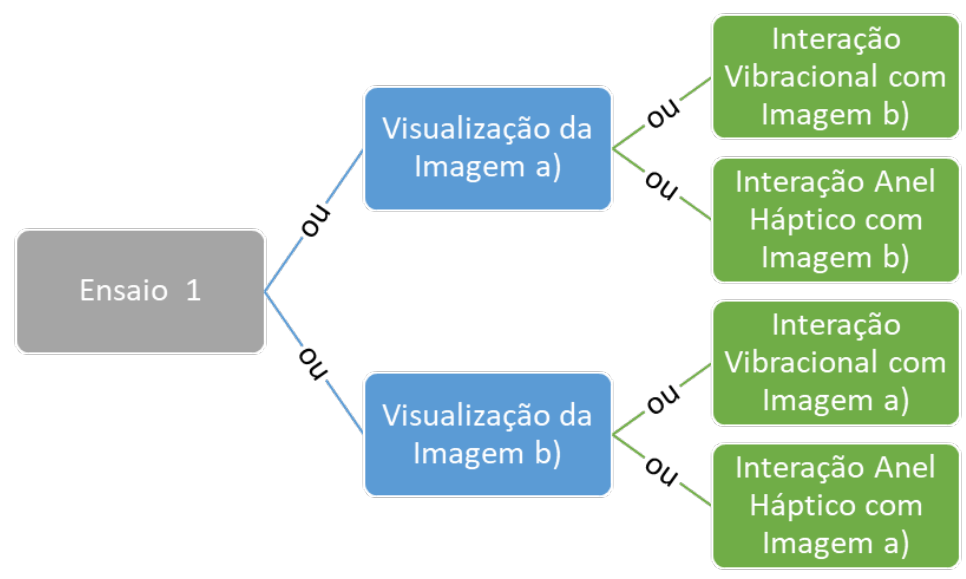

Fonte: Os autores (2017)

A intenção deste ensaio foi identificar se ocorre ou não um ganho subjetivo de qualidade ao avaliar uma imagem somente pelo canal visual em comparação ao canal visual e tátil. Para tanto, foi solicitado que cada participante observasse a primeira imagem durante 30 segundos. Após, ocultando a imagem foi solicitado que descrevessem a mesma com suas próprias palavras. Na sequência do ensaio, foi realizada uma segunda interação utilizando da visualização e também do rastreio da imagem no dispositivo utilizando anel háptico ou dispositivo padrão para possibilitar a percepção de retorno vibracional proporcionada pelo aplicativo, conforme Figura 5.

Figura 5 - Interação dos participantes durante o ensaio.
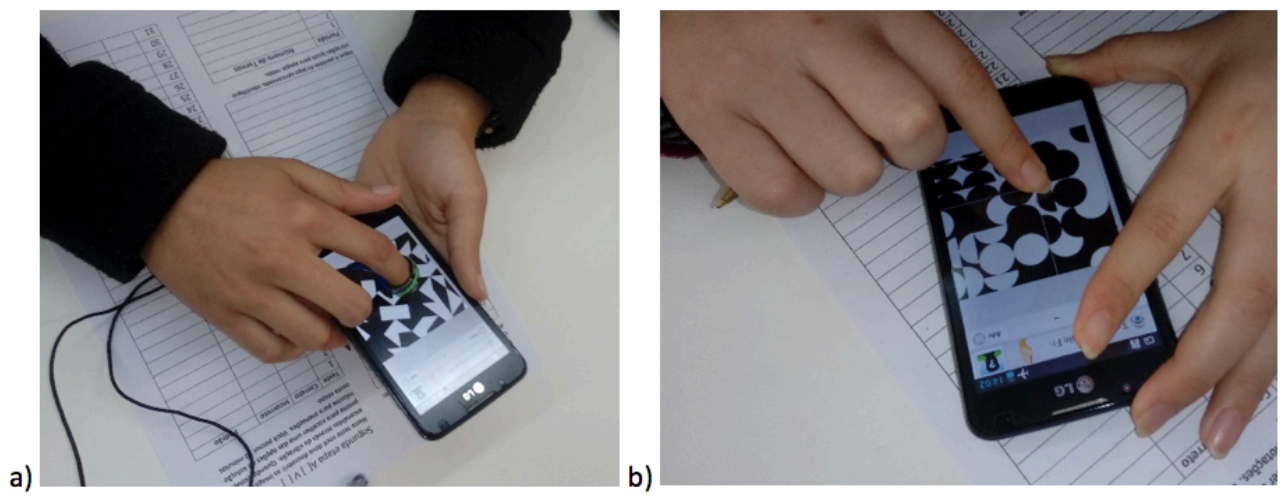

Fonte: Os autores (2017)

Na imagem a) o usuário veste o anel háptico e interage com o dispositivo móvel, na imagem 130 Congresso Brasileiro de Pesquisa e Desenvolvimento em Design, Univille, Joinville (SC) 
b) o usuário interage com a tela do dispositivo percebendo o retorno vibracional do motor interno do aparelho. Após 30 segundos de interação, a imagem foi novamente ocultada e foi solicitado a cada participante que descrevesse a imagem apresentada com as suas próprias palavras. Os momentos de descrição ocorreram sem limite de tempo, sendo que foi dado prosseguimento ao estudo após o participante dar como encerrada a sua exposição.

\subsection{Ensaio B - Padrões Vibracionais}

Neste ensaio, foi solicitado aos participantes efetuassem seis partidas completas do jogo de memória no aplicativo Haptic Memory Match utilizando o recurso vibracional, conforme Figura 6.

Figura 6 - Interação com o Jogo da Memória.
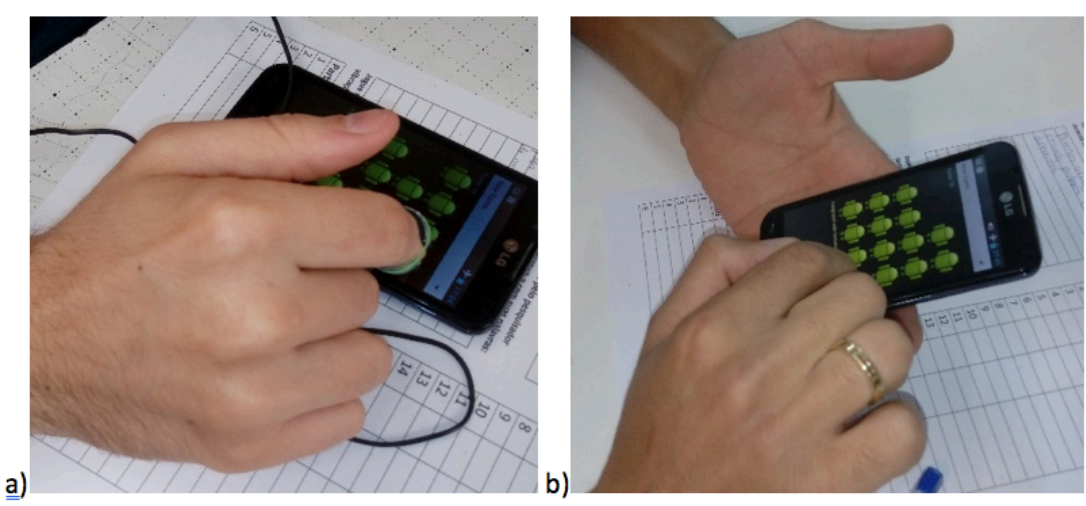

Fonte: Os autores (2017)

A imagem a) demonstra o uso do anel háptico durante uma partida e na imagem b) a interação de outro participante diretamente com a tela do dispositivo. A cada partida realizada, o participante deveria realizar oito combinações de ícones vibracionais e anotar o número de tentativas totais (indicado pelo aplicativo) até o encerramento da partida. Este ensaio teve como objetivo o estudo do reconhecimento da forma, solicitando do participante a identificação de partes com vibração iguais em meio a informações táteis diversas. Não foi estipulado limite de tempo para execução das partidas.

\subsection{Ensaio C - Objetos Hápticos}

Foi solicitado que os participantes identificassem através do rastreio de vibração imagens táteis no aplicativo Haptic Mystery. Os participantes utilizaram ou o a) anel háptico ou a b) vibração do aparelho durante a execução do teste, Figura 7, que foi cronometrada para o tempo limite de 10 (dez) minutos ou até 31 (trinta e um) testes. 
Figura 7 - Interação com a imagem tátil escondida
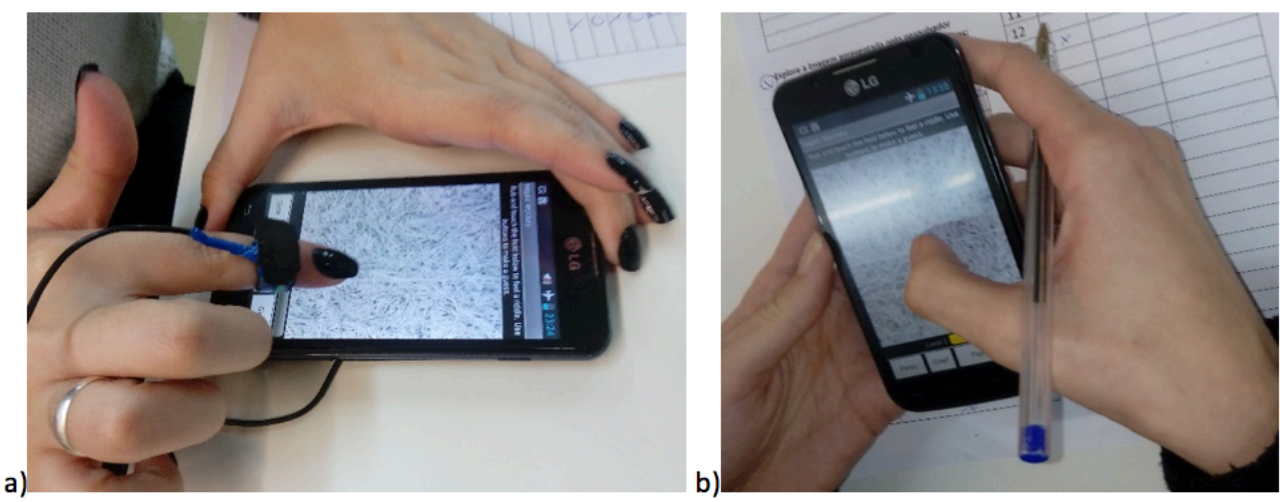

Fonte: Os autores (2017)

O aplicativo possui um total de 320 padrões táteis distribuídos em 30 níveis de dificuldade. Durante a execução dos testes, o nível máximo alcançado foi o quarto, por apenas um participante. A cada interação quatro opções de resposta eram oferecidas na base da interface e conforme seleção o aplicativo demonstra a imagem tátil que estava oculta e indica o acerto ou erro do participante. Os erros ou acertos foram anotados pelo próprio participante ou pelo pesquisador conforme preferência de cada voluntário. Este ensaio teve como objetivo avaliar o reconhecimento de padrões grafo-táteis.

\section{Resultados}

Nesta seção, são apresentados sinteticamente os resultados bem como as considerações em formato quali-quantitativo.

\subsection{Resultados do Ensaio 1}

Mombach e Welfer (2013) consideram que interações sensoriais mais ricas ou com mais canais sensoriais de informação possibilitam um detalhamento maior na descrição de objetos. Assim, buscou-se compreender se a qualidade tátil da segunda interação poderia influenciar diretamente na percepção subjetiva da imagem e consequentemente em descrições mais ricas do objeto visualizado. Para tanto, as respostas de cada participante foram transferidas para meio digital, como exemplo:

- Visualização Imagem a); a imagem é uma composição dentro de um espaço quadrado através da repetição de um módulo composto de formas, como triângulos $e$ retângulos, dispostas de forma peculiar. Considerando que esses módulos não sejam o fundo, podemos dizer que estes estão em preto e se interseccionam (formas), e o fundo está em branco. (52 palavras)

- Interação Vibracional Imagem a); a imagem é bem mais métrica e composta por quadrados e fragmentos. É interessante que, além das áreas visuais delimitadas, ocorre uma extrapolação para o meio físico ou uma ampliação sensorial do sentido por mim. (35 palavras) 
Com base nas descrições realizadas realizou-se inicialmente uma análise quantitativa através de uma contagem simples de palavras, conforme Quadro 1.

Quadro 1 - Contagem de palavras.

\begin{tabular}{|l|c|}
\hline \multicolumn{1}{|c|}{ Modo de Interação } & Total de palavras \\
\hline Somente visual & 651 \\
\hline Visual e interação vibracional & 495 \\
\hline Visual e interação com anel háptico & 411 \\
\hline (VIV + VIA) - SV & 255 \\
\hline
\end{tabular}

Fonte: Os autores (2017)

Considerando que um número maior de elementos descritivos pode ser relacionado com experiências informacionais mais ricas, conforme sugerido por Mombach e Welfer (2013), pode-se assumir através do resultado quantitativo que o uso do canal tátil foi percebido como incremento da informação. As interações visuais com o anel háptico e com a vibração interna do aparelho produziram 255 mais palavras do que a interação simplesmente visual. No entanto, para a verificação qualitativa discurso, foram analisadas todas as descrições realizadas considerando os seguintes aspectos:

- A (visual ou háptico); a descrição discorre sob o objeto de estudo "imagem"; considera características como cor, formato geométrico, disposição.

- B (visual ou háptico); a descrição atribui significado tátil à imagem; atribui relações como rugosidade, arrasto, textura.

- C (visual ou háptico); a descrição atribui significado ao objeto de estudo "imagem"; atribui referências e analogias para explicar as percepções.

- D (visual ou háptico); a descrição discorre sobre a interação tátil; discorre sobre a forma que a interação se desenvolve, mas não acrescenta valor à descrição da imagem.

Como exemplo a seguinte composição:

- A imagem apresenta círculos pretos e brancos, Aháp (classificação A na interação háptica); simples descrição da imagem observada.

- Parece formar um pinheiro; Cháp (classificação C na interação háptica); o participante recorre a referências imagéticas, construindo analogias.

- Ao arrastar o dedo na parte branca não ocorre vibração, Dháp (classificação D na interação háptica); o participante apenas relata um fato de ação e reação.

- Na parte preta ela está "viva" e vibra, ao arrastar o dedo a vibração continua. Bháp (classificação B na interação háptica); o participante atribui significado à cor como uma cor viva que vibra ao ser tocada.

Desta forma, as descrições dos participantes apresentadas anteriormente foram classificadas em A - B - C - D discriminando a ensaio visual (vis) e a ensaio háptica (háp) e são apresentadas sinteticamente no Quadro 2: 
Quadro 2 - Classificação das frases

\begin{tabular}{|l|l|l|l|l|l|l|l|l|l|}
\hline Aspecto considerado & Avis & Bvis & Cvis & Dvis & Aháp & Bháp & Cháp & Dháp \\
\hline Total de frases identificadas & 85 & 1 & 33 & 0 & 46 & 19 & 14 & 35 \\
\hline
\end{tabular}

Fonte: Os autores (2017)

Os resultados quantitativos deste ensaio demonstram que o acréscimo do canal sensorial tátil reduziu as caracterizações das imagens em comparação à descrição somente pela observação visual. Um dos possíveis motivos que podem ser relacionados a este resultado é a falta de um período de adaptação dos participantes. Como não houve este momento de reconhecimento do dispositivo com retorno háptico, acredita-se que muitos participantes relataram aspectos desta experiência de interação, não se atendo somente ao solicitado na atividade.

\subsection{Resultados do Ensaio 2}

Neste ensaio foi considerado o reconhecimento da forma, ou seja, foram considerados os padrões vibracionais apresentados no aplicativo e a capacidade de reconhecimento dos participantes. Como primeira parte da análise foram considerados os dados de interação utilizando anel háptico e da interação com a vibração padrão do dispositivo, conforme Tabela 1:

Tabela 1 - Resultados da interação com padrões vibracionais

\begin{tabular}{l|c|c|c|c|c|c|l|l}
\hline \multicolumn{7}{c}{ Resultados da interação com anel háptico - 15 participantes } \\
\hline Partidas & I & II & III & IV & V & V I & & \\
\hline Mediana & 34,0 & 27,0 & 29,0 & 28,0 & 28,0 & 34,0 & Mediana Total & 28,0 \\
\hline Média & 35,5 & 27,3 & 32,4 & 29,1 & 29,7 & 33,3 & Média Total & 31,3 \\
\hline \multicolumn{10}{|c|}{ Resultados da interação com vibração padrão - 16 participantes } \\
\hline Partidas & I & II & III & IV & V & VI & & \\
\hline Mediana & 31,5 & 33,5 & 31,5 & 27,0 & 27,0 & 32,5 & Mediana Total & 31,0 \\
\hline Média & 31,6 & 34,5 & 34,4 & 28,4 & 29,2 & 31,7 & Média Total & 31,6 \\
\hline
\end{tabular}

Fonte: Os autores (2017)

Apesar do número de amostras para os modos de interação não terem sido idênticos, considerou-se aqui o erro amostral desprezível uma vez que os resultados alcançados pelos participantes ter sido bastante equilibrado ao longo dos ensaios de interação. No entanto, sugerese cautela pelo número amostral reduzido de participantes. Considerando os dados coletados, não é possível afirmar que uma ou outra modalidade de interação ofereceu maior facilidade em discriminar as vibrações, sendo que a média interações registradas nas duas modalidades testadas foi bastante aproximada. Quanto à mediana, existe uma diferença um pouco mais acentuada, com $10 \%$ de vantagem (menor número de tentativas) para a interação com o anel háptico.

Também pode-se observar através dos dados que nas interações com o anel háptico houve uma variação mais expressiva entre a primeira e a segunda interação, o que pode sugerir um entendimento maior dos padrões vibracionais pelo participante reduzindo a ocorrência de erros. Como aponta Peña (2013) uma vez que o que é visto e percebido é localizado no mesmo espaço, na interação com o anel háptico, pode-se ter uma facilidade maior no entendimento do objeto que é explorado. No entanto, este resultado não é suficientemente expressivo para afirmar que de fato 
ocorreu tal interpretação facilitada pelos usuários. O comportamento das interações com o sistema vibracional padrão, não foi muito diferente, pode-se observar um número maior tentativas até a terceira partida, mas após esta os resultados se aproximam e há até mesmo uma tendência para o componente vibracional padrão.

Por fim, analisando a última partida nos dois modos de interação observou-se um resultado negativo, o que pode indicar fadiga sensorial. Almeida (2017), indica a possibilidade de o participante apresentar fadiga sensorial após longa exposição a estímulos. Ou seja, o excesso de estímulos vibracionais (na última partida os usuários já haviam sido submetidos em média a 316 vibrações) pode ter exaurido o sistema sensorial tátil e reduzido a acurácia do usuário. No entanto, para identificar a origem real desta ocorrência de erros, devem ainda ser considerados outros fatores, como a redução do interesse do participante, a ausência de uma recompensa ao participante e a influência da presença do pesquisador.

\subsection{Resultados do Ensaio 3}

Neste ensaio, os participantes foram desafiados a identificar através do tato representações gráficas ou grafo-tátil de imagens "escondidas" na tela do dispositivo utilizando um dos modos de interação, com anel háptico ou vibração padrão do dispositivo. A cada participante foi oferecido um tempo máximo de interação de 10 minutos ou até ter completado 31 testes. Os cálculos de média e mediana para os resultados alcançados, Tabela 2, consideraram o total de interações, total de acertos e a interação com anel háptico ou vibração padrão.

Tabela 2 - Cálculo de Média e Mediana no Ensaio 3.

\begin{tabular}{l|c|c|c|c}
\hline & Total de Interações & Total de Acertos & \% de acertos & Tempo (s) \\
\hline MEDIANA (Total) & 20 & 14 & 68 & 30 \\
\hline MÉDIA (Total) & 21 & 14 & 65 & 35 \\
\hline MEDIANA (Anel Háptico) & 20 & 12 & 65 & 30 \\
\hline MÉDIA (Anel Háptico) & 20 & 12 & 64 & 36 \\
\hline MEDIANA (Vibração) & 24 & 17 & 71 & 25 \\
\hline MÉDIA (Vibração) & 23 & 15 & 66 & 34 \\
\hline
\end{tabular}

Fonte: Os autores (2017)

Através dos dados coletados observou-se que as interações utilizando o sistema vibracional padrão apresentaram um maior número de acertos, tanto em valor numérico quanto percentual. 0 total de interações superior à média pode também estar vinculado a um avanço mais rápido no aplicativo. Aferiu-se o valor mediano de 25 segundos, ou seja, cada imagem tátil demandou menos de meio minuto para levar a escolha de uma solução pelo participante. Em comparação a interação com o anel háptico solicitou um tempo mediano de 30 segundos, o que pode significar uma maior dificuldade no entendimento das representações gráficas apesar da proximidade entre o ponto de contato e o retorno tátil vibracional. No entanto o número de acertos entre as modalidades não possui diferença significante, sendo apenas $2 \%$ superior comparando as médias entre os modos de vibração e interação háptica ou pela mediana $6 \%$. Assim, pode-se considerar que as duas formas de interação provêm resultados similares, mas que aparentemente a vibração padrão foi mais efetiva na compreensão das representações gráficas. 


\section{Conclusões}

O ensaio de interação desenvolveu três práticas com a intenção de aprofundar o conhecimento sobre o retorno tátil em dispositivos móveis. Dentro dos limites desta investigação observou-se que a compreensão de informações táteis ocorre mesmo com o uso de vibrações de pouca resolução, como a fornecida pelos dispositivos móveis testados. A reduzida capacidade de promover interações mais complexas dos motores vibracionais é bastante relatada na literatura, como em Gorlewicz et al. (2014) e parece ter sido corroborada pelos resultados dos testes realizados nos quais a incidência de erros foi relevante, independente da modalidade de interação.

Entre as abordagens testadas, não se pode considerar os resultados encontrados como conclusivos ou definitivos. No entanto, é possível considerar uma tendência de maior efetividade no reconhecimento de padrões vibracionais através do anel háptico conforme observado no Ensaio B. Contudo, durante os outros testes o anel háptico apresentou qualidade similar à da vibração padrão do dispositivo móvel.

Assim, apesar de não ser possível trazer resultados absolutos, os ensaios reforçam à importância de utilizar dispositivos móveis com retorno tátil adequados às aplicações. Por exemplo, o uso de motores vibracionais pode ser prático na descoberta de informações de baixa complexidade ou sem risco para o usuário, mas dados mais complexos ainda parecem depender de canais auxiliares, como visual e auditivo, ou ainda do desenvolvimento de novos aparatos para reprodução de informações táteis.

Finamente, destaca-se a demanda por novos ensaios sobre esta temática para determinar quais padrões são efetivos para identificação puramente tátil. Ensaios futuros poderiam também medir a incidência de erros oriundos da técnica de rastreio utilizada pelo usuário ou das limitações de processamento do dispositivo móvel. Há também que se considerar a possibilidade de outras tecnologias promoverem resoluções de retorno tátil mais precisas ou melhor combinadas com outras modalidades sensoriais, o que abriria novas oportunidades no campo do retorno tátil em dispositivos móveis.

\section{Agradecimentos}

Os autores agradecem à CAPES e ao CNPq pelo apoio na forma de bolsa de estudos e bolsa de produtividade em pesquisa. Este estudo é resultado parcial de tese de doutorado.

\section{Referências}

ALMEIDA, M. DA G. DE S. Ver além do visível: a imagem fora dos olhos, 2017. PUC-Rio.

GORLEWICZ, J.; BURGNER, J.; BURGNER, T. J.; WEBSTER, R. J. Initial experiences using vibratory touchscreens to display graphical math concepts to students with blindness. Journal of Special Education Technology, v. 29, n. 2, p. 17-25, 2014.

LIBERTO, A. DA C. C. A perceção grafo-tátil de imagens no aluno cego. 2012. Universidade Católica Portuguesa

MOMBACH, J. G.; WELFER, D. Proposta de um aplicativo móvel para percepção de imagens estáticas por alunos com deficiência visual. Brazilian Symposium on Computers in Education (Simpósio Brasileiro de Informática na Educação - SBIE), v. 24, n. 1, p. 487, 2013. Disponível em: <http://www.br-ie.org/pub/index.php/sbie/article/view/2527>. 
PEÑA, G. A. M. DE LA. Drawings Made by Visually Impaired Persons: an Essential Strategy on Haptic Graphic Design. Senses\&Sensibility'13 Proceedings Book, p. 226-234, 2013. IADE - Creative University/Edições IADE.

TOENNIES, J. L.; BURGNER, J.; WITHROW, T. J.; WEBSTER, R. J. Toward haptic/aural touchscreen display of graphical mathematics for the education of blind students. World Haptics Conference (WHC), 2011 IEEE, p.373-378, 2011. IEEE. 